\title{
NOTCH1 Gene Mutation
}

National Cancer Institute

\section{Source}

National Cancer Institute. NOTCH1 Gene Mutation. NCI Thesaurus. Code C45403.

A change in the nucleotide sequence of the NOTCH1 gene. 